\title{
DESAFIOS DA FORMAÇÃO DO ENFERMEIRO NO CONTEXTO DA EXPANSÃO DO ENSINO SUPERIOR ${ }^{a}$
}

\author{
Nursing education challenges in a context of growth in participation in higher \\ education
Desafíos de la formación del enfermero dentro del contexto de expansión de la enseñanza superior

Kênia Lara Silva

Tatiana Silva Tavares ${ }^{4}$
Roseni Rosângela Sena²

Paloma Morais Silva ${ }^{5}$
Marília Rezende Silveira ${ }^{3}$

\section{RESUMO}

0 estudo teve como objetivo identificar desafios na formação do enfermeiro no contexto da expansão do ensino superior. Pesquisa realizada em 17 cursos de graduação em enfermagem no Estado de Minas Gerais, por meio de grupos focais com docentes e discentes. Os resultados indicam que há uma mudança no perfil dos alunos que têm ingressado nos cursos de enfermagem. No contexto da expansão, as escolas têm contribuído para a transformação dos modelos de atenção com a incorporação de uma nova concepção sobre o sistema de saúde. Contudo, há desafios para associar as mudanças requeridas na graduação com o novo perfil de alunos que "optam" pelos cursos de enfermagem. Indica-se a necessidade de as escolas reverem seu projeto pedagógico e sua organização curricular a favor da qualificação do cuidado e da transformação dos modelos de atenção em saúde.

Palavras-chave: Educação em enfermagem. Instituições de ensino superior. Ensino de graduação.

\begin{abstract}
This study aimed to identify aspects that challenge nursing education in a context of growth in participation in higher education. The research was conducted in 17 Bachelor of Nursing courses in the state of Minas Gerais with focus groups formed by professors and students. The results indicate changes in the profile of nursing students being admitted to the universities. In this context of growth nursing schools have contributed to the transformation of the models of care and to the incorporation of new concepts on health system. However there are problems to articulate the changes required in the nursing degree courses with the new profile of students that decide on a nursing course. It is necessary that the schools review their teaching project and the organization of the curriculum that should focus on care qualification and the transformation of the health care system.
\end{abstract}

Keywords: Nursing Education. Higher Education Institutions. Teaching in Degree Courses

\section{Resumen}

El presente estudio tuvo por objeto identificar los desafíos de la formación del enfermero dentro del contexto de expansión de la enseñanza superior. Se trata de una investigación realizada en 17 cursos de graduación en Enfermería en el Estado de Minas Gerais, con grupos focales de docentes y alumnos. Los resultados indican que el perfil de los alumnos que ingresan en los cursos de enfermería ha cambiado. Dentro del contexto de expansión, las facultades han contribuido para transformar los modelos de atención al adoptar una nueva concepción sobre el sistema de salud. Sin embargo, deben enfrentarse desafíos para asociar los cambios requeridos en la graduación con el nuevo perfil de alumnos que optan por los cursos de Enfermería. Se señala la necesidad de que las escuelas revean su proyecto pedagógico y organización curricular a favor de la calificación del cuidado y transformación de los modelos de atención en salud.

Palabras Clave: Educación en Enfermería. Instituciones de Enseñanza Superior. Enseñanza de Grado.

\footnotetext{
${ }^{1}$ Enfermeira. Doutora em Enfermagem. Professora Adjunta da Escola de Enfermagem da UFMG. Sub-coordenadora do Núcleo de Estudos e Pesquisas sobre Ensino e Prática de Enfermagem (NUPEPE) da Escola de Enfermagem da UFMG. Belo Horizonte - MG. Brasil. E-mail: kenialara17@yahoo.com.br, ${ }^{2}$ Enfermeira. Doutora em Enfermagem. Professora Emérita da Escola de Enfermagem da UFMG. Coordenadora do NUPEPE. Belo Horizonte - MG. Brasil. E-mail: rosenisena@uol.com.br , '3Enfermeira. Doutora em Enfermagem. Professora Adjunta da Escola de Enfermagem da UFMG. Pesquisadora do NUPEPE. Belo Horizonte - MG. Brasil. E-mail: lylasilveira@hotmail.com, ${ }^{4}$ Enfermeira. Mestranda do Programa de pós-graduação em Enfermagem da Escola de Enfermagem da UFMG, bolsista da FAPEMIG, pesquisadora do NUPEPE. Belo Horizonte - MG. Brasil. E-mail: tatianasilvatavares@yahoo.com.br, ${ }^{5}$ Enfermeira. Mestranda do Programa de pós-graduação em Enfermagem da Escola de Enfermagem da UFMG, pesquisadora do NUPEPE. Belo Horizonte - MG. Brasil. E-mail: palomamorais@ymail.com
} 


\section{INTRODUÇÃO}

A graduação dos profissionais de saúde tem sido o foco de referência quando se discute a formação na área, com críticas contundentes. A principal delas é que a tradição nesse campo é de uma formação centrada em conteúdos desconectados da realidade dos serviços de saúde, sem uma orientação integradora entre ensino e trabalho que inclua o enfrentamento das necessidades de saúde da população e o desenvolvimento do sistema de saúde ${ }^{1}$.

Nesse campo, insere-se a formação de enfermeiros que apresenta os mesmos desafios para empregar transformações em seus modelos, com relevância no contexto social e orientada pelos problemas da realidade concreta, incorporando análises prospectivas das práticas da profissão, em contextos de inovações tecnológicas, de mudanças nos serviços de saúde e no perfil epidemiológico e demográfico da população.

Desde a promulgação da Lei do Exercício Profissional de Enfermagem, em 1986, há um intenso movimento acerca da regulamentação das ações dos profissionais de enfermagem que influenciam as formulações do processo ensinoaprendizagem dos enfermeiros, em função das mudanças nas políticas de saúde e nos modelos assistenciais².

A promulgação da Lei de Diretrizes e Bases da Educação Nacional (LDB), 1996, estabeleceu as diretrizes gerais para a formação superior no país, permitindo autonomia política e administrativa das instituições de ensino superior ${ }^{3}$. Nesse movimento, a partir de 1997, as Escolas de Enfermagem do Brasil iniciam a implantação do denominado Novo Currículo, tendo como referencial a $L D B$, o que exigiu reordenação e readequação das estruturas acadêmico-administrativas das escolas e um programa de capacitação docente para concretizar o propósito de transformação do modelo de formação do enfermeiro.

Em 2001, as Diretrizes Curriculares Nacionais (DCN) para o Curso de Graduação em Enfermagem foram aprovadas pelo MEC, estabelecendo, dentre outros aspectos, as competências e habilidades a serem desenvolvidas no processo de formação do enfermeiro. As DCN definem, ainda, que o perfil dos profissionais de enfermagem deve abranger uma formação generalista, crítica e reflexiva ${ }^{4}$.

A implantação das DCN representa uma estratégia fundamental no redirecionamento da formação dos profissionais de enfermagem, fundamentando-se em um novo marco estruturante para a educação de enfermagem: a orientação da formação para impulsionar a efetivação dos princípios do Sistema Único de Saúde (SUS). Além disso, a formação deve atender às necessidades de saúde da população, por meio da integralidade da atenção e pela qualidade e humanização do atendimento ${ }^{5}$.

Ao longo dos últimos 30 anos, temos defendido que, para o alcance de uma proposta de atenção à saúde mais justa, igualitária e de qualidade, deve haver uma integração das demandas políticas e sociais aos interesses locais. A partir das Diretrizes Curriculares Nacionais, as instituições formadoras em enfermagem devem potencializar espaços que permitam 0 desenvolvimento da pesquisa, extensão e formação associado a sua inserção no sistema público de saúde ${ }^{6}$.

Percebe-se, nesse cenário, um avanço gradual na política de formação de profissionais de saúde, em especial da enfermagem, em que se busca uma articulação com as políticas de educação e de saúde. Pode-se afirmar que, no Brasil, nos últimos anos, houve uma modulação nos cursos de graduação em Enfermagem que aproxima do proposto nas Diretrizes Curriculares com os princípios do sistema público de saúde. Porém, essa proposta disputa espaço com a tendência de a formação ser orientada pelo mercado e pela competição.

Dessa forma, tomou-se como problematização para o estudo o movimento brasileiro de expansão do ensino superior. Na área da Enfermagem, houve um aumento de cinco vezes no número de vagas nos cursos de graduação em enfermagem, passando de 5.000 vagas no final da década de 1990 para cerca de 35.000 no início dos anos $2000^{7}$. Observou-se também o aumento do número de cursos em todo o Brasil, sendo que os da rede pública passaram de 61 em 1991, para 93 em 2004, e na na rede privada passaram de 45 para 322, no mesmo período ${ }^{8}$ que se pressupõe estar relacionado à autonomia pedagógica, administrativa e de gestão financeira das instituições de ensino alcançada com a LDB e a uma frágil regulação da educação superior no País. Visualizamos que essa expansão pode proporcionar uma democratização do acesso ao ensino superior e maior disponibilidade de profissionais graduados no mercado, o que, por sua vez, pode melhorar a qualidade do cuidado prestado.

Assim, a perspectiva da aproximação do processo de formação com as políticas de saúde deve ser expressa nos projetos políticos dos cursos de Enfermagem em cada instituição, desenvolvendo mecanismos que garantam um padrão de qualidade e minimizando os efeitos deletérios da ampliação da oferta de vagas no ensino superior unicamente com a perspectiva mercantil ${ }^{9}$. Em especial, visualiza-se que o contexto da graduação em Enfermagem no Brasil pode possibilitar a qualificação de profissionais da área de saúde, em especial de técnicos de enfermagem, e repercutir positivamente na transformação dos modelos de atenção em saúde.

Nessa perspectiva, o estudo tem como objetivo identificar os desafios para a formação do enfermeiro no contexto da expansão dos cursos de graduação em enfermagem.

\section{METODOLOGIA}

Trata-se de um estudo descritivo-exploratório, com abordagem qualitativa, ancorado no referencial teórico e metodológico da dialética.

Na compreensão do processo de formação do enfermeiro, a opção pela dialética fundamenta-se na 
possibilidade dessa corrente teórico-metodológica de permitir a compreensão e a explicação das práticas pedagógicas, das ações educativas e, principalmente, das relações da escola com o todo social'. Além disso, "a educação é vista como uma prática nas formações sociais e resulta de suas determinações econômicas, sociais e políticas; faz parte da supraestrutura (...)" 9:104.

Em fevereiro de 2010 foram identificados, por meio do banco de dados e-MEC do Ministério da Educação, 126 cursos de graduação em Enfermagem no Estado de Minas Gerais, aos quais foram aplicados critérios de inclusão para se definirem os cenários do estudo. Definiu-se como critério a inclusão de uma instituição de ensino pública e uma privada de cada uma das 13 macrorregiões de saúde do Estado. Nas regiões onde havia mais de uma escola com a mesma categoria administrativa foi realizado um sorteio aleatório para se definir o cenário por macrorregião.

Em cada cenário realizou-se um grupo focal com docentes e um grupo focal com estudantes das escolas selecionadas, totalizando 34 grupos realizados, em 17 instituições, sendo 12 privadas e cinco públicas. Participaram dos grupos focais 100 professores e 140 alunos.

Optou-se pela utilização de grupos focais, pois tal técnica permite o diálogo entre os sujeitos de forma não diretiva, buscando a reflexão dos envolvidos e a coleta de informações ${ }^{10}$. Os grupos focais foram direcionados pela questão norteadora: "Descrevam como vocês percebem que a formação do enfermeiro nesta instituição prepara vocês para o trabalho em saúde, considerando as políticas de saúde vigentes".

Os dados provenientes dos grupos focais foram submetidos à Análise de Conteúdo Temática ${ }^{11}$ da qual emergiram duas categorias empíricas: 0 perfil dos alunos nos cursos de Enfermagem: desafio para a formação; e A graduação em Enfermagem: desafios para a transformação do modelo de atenção em saúde. Na apresentação dos resultados, os temas são exemplificados com trechos dos depoimentos dos participantes codificados com as letras GFP, quando se trata de discurso de professor, e GFA, quando se trata de discurso de alunos, ordenados de 1 a 17 pela sequência de realização dos grupos focais.

A pesquisa respeitou a Resolução 196/96 do Ministério da Saúde, sendo aprovada pelo Comitê de Ética em Pesquisa da Universidade Federal de Minas Gerais (ETIC 435/08). Os sujeitos foram informados sobre os objetivos e finalidades do estudo e assinaram o Termo de Consentimento Livre e Esclarecido.

\section{RESULTADOS E DISCUSSÃO}

Os resultados permitiram identificar desafios inerentes à formação do enfermeiro no contexto da expansão do ensino superior. Destacamos dois aspectos inter-relacionados: o perfil dos estudantes dos cursos de Enfermagem e as implicações para a transformação do modelo de atenção à saúde.

\section{Primeiro desafio: o perfil dos estudantes nos cursos de Enfermagem}

A análise dos dados evidencia que os participantes do estudo reconhecem uma mudança no perfil dos alunos que têm ingressado nos cursos de graduação em Enfermagem nos últimos anos. Esse novo perfil é composto por alunos já inseridos no mercado de trabalho, na área de saúde ou não. Entre os que trabalham na área de saúde estão os técnicos de enfermagem, os agentes comunitários de saúde e os profissionais que atuam em cargos administrativos ou de apoio nos serviços de saúde, como retratam os seguintes trechos:

A grande dificuldade hoje é a questão dos alunos que estão chegando pra gente, com essa facilidade enorme de recurso (...). É agente comunitário, é técnico de enfermagem. (GFP Escola 6)

E tem alguns alunos que falam com a gente 'eu tô formando, eu sou técnico, eu tô formando para eu me aposentar numa posição melhor'. (GFP Escola 2)

Aqueles que já trabalhavam como técnicos, eles já vislumbram uma ascensão profissional, hoje a maior parte dos nossos alunos já trabalharam como técnico de enfermagem, hoje eles têm sua ascensão profissional. (GFP Escola 7)

0 grupo de alunos já com inserção no trabalho em saúde relata que a busca pela graduação representa oportunidade de ascensão profissional e melhoria salarial, corroborando os resultados de estudos que analisam a opção pelo curso superior de enfermagem dada a possibilidade de crescimento pessoal e profissional, aquisição de conhecimentos e perspectivas de mudança de nível dentro da equipe ${ }^{12}$.

Os técnicos de enfermagem, principalmente, por sua experiência prática, têm o domínio das técnicas, com a oportunidade, na graduação, de se dedicar a questões teóricas e refletir sobre desafios da atuação profissional. Contudo, os participantes relatam a dificuldade da maioria dos egressos em acessar ou ascender no mercado de trabalho após se formar, como evidenciado nos discursos a seguir:

Bom, aqui, infelizmente, a gente já tem que fazer o curso já imaginando que você vai embora, ou então você vai ficar aqui desempregado. (GFA Escola 2)

Tá cada vez mais difícil você encontrar seu lugar ao sol, ainda mais aqui na região;e tem muitas faculdades aqui na cidade que tem curso de enfermagem oferecendo, então aqui mesmo é bem saturado o mercado de trabalho. (GFA Escola 5) 
Sou técnico de enfermagem e trabalho no hospital já. Eu escolhi o curso de enfermagem, porque já estava dentro mais ou menos da minha área, e eu pretendo, assim que formar, não ficar [no município] não, porque infelizmente, aqui na cidade por enquanto só tem dois hospitais. Então pra entrar aqui a concorrência é muito grande, muito acirrada mesmo. (GFA Escola 8)

Os discursos apresentados remetem à discussão de que o desemprego passa a configurar-se como uma tendência do mercado de trabalho da enfermagem, contrariando dados de estudo realizado na área ${ }^{13}$. Em parte, essa tendência devese ao grande número de formados, em especial no contexto da expansão das escolas, sem estreita relação com as análises de oferta no mercado de trabalho, bem como ao pequeno crescimento do emprego para as categorias do pessoal de enfermagem ${ }^{14}$.

Estudo desenvolvido com base nos dados da Relação Anual de Informações Sociais (RAIS), do Ministério do Trabalho e Emprego, buscando analisar a evolução e a estrutura recente dos mercados de trabalho formal em saúde no Brasil, evidenciou que o pessoal de enfermagem apresentou no período de 1990 a 2000 crescimento em torno de $40 \%$ a 50\% para a região Sudeste. Em relação à geração de empregos assalariados nos mercados de trabalho na saúde, a administração pública e as atividades de atenção hospitalar constituem-se nas classes de maior importância. Constatou-se um aumento significativo do emprego para os auxiliares de enfermagem e, em menor escala, uma queda do emprego de outras categorias de pessoal de enfermagem ${ }^{14}$.

Em relação ao grupo de alunos que ingressam nos cursos de enfermagem sem inserção prévia no mercado de trabalho na área da saúde, geralmente recém-egressos do ensino médio, os participantes do estudo abordam que em geral estes desconhecem a profissão e são imaturos para cursar o ensino superior, o que compromete a formação.

Bom, eu vejo que a grande dificuldade é que o aluno, não só que chega pra enfermagem, mas para os outros cursos, é um aluno que chega hoje em dia com um déficit muito grande na educação, é um aluno que vem de projetos que tem no segundo grau, esses projetos do governo, seis meses cada série, são muitos os alunos que hoje em dia já trabalham no sistema, já vivenciam uma série de situações que não são as situações corretas. Então quebrar esses tabus e resgatar esse aluno é a maior dificuldade. (GFP Escola 6)

O acadêmico, ele chega aqui na Universidade muito cru, eu acho que ele nem tem noção do que é uma universidade, então muitas vezes quando você chega no final do período que vai ver as possibilidades que você tem de desenvolver a sua formação; você vai ver que poderia ter aproveitado melhor. (GFA Escola 4)

Acho que a gente entra na universidade um pouco imaturo, a gente não sabe se é, às vezes, a enfermagem realmente que você quer, ou se você queria medicina, ou se você queria outro curso que não tem nada a ver. (GFA Escola 1)

Evidenciou-se que, na percepção dos participantes dos grupos focais, ambos os grupos de alunos - com ou sem inserção no mercado de trabalho em saúde - procuram o curso de graduação motivados pela facilidade de acesso, possibilitada pelo aumento do número de vagas no ensino superior no país, pela flexibilidade das formas de ingresso e pela oportunidade de vislumbrar melhores condições salariais.

A facilidade do acesso universitário tem sido proporcionada por programas do Ministério da Educação (MEC) de fornecimento de bolsas de estudos ou financiamento, com destaque para o Programa Universidade para Todos (PROUNI) e o Programa de Financiamento Estudantil (FIES) ${ }^{15}$. Além disso, as próprias faculdades privadas de Enfermagem têm atraído discentes por meio do oferecimento de bolsas de estudo e abertura de unidades próximas à periferia das grandes cidades $^{12}$.

As mudanças no perfil dos estudantes dos cursos de graduação em enfermagem repercutem em desafios para a formação, como lidar com o despreparo do aluno para cursar o ensino superior, devido ao déficit de conhecimento prévio relacionado à defasagem de conteúdos do ensino fundamental e médio, enfatizado pelos professores participantes do estudo:

A maior angústia do educador do ensino superior é a falta de base do educando no ensino médio e, às vezes, até no fundamental, que é de não saber nem escrever direito. É uma tristeza quando você pede alguém para ler um texto pra você, (...) não sabe ler, começa a tremer, dá sudorese de tanto medo, pavor da leitura. Então, essa dificuldade que eu tenho sentido nos últimos cinco anos com cada turma que inicia. A dificuldade é com o despreparo deles para chegar no ensino superior. Eu tenho um medo muito grande de a gente chegar em um determinado momento em que a gente vai ter a maioria, a maior parte da população, com ensino superior, dessa maior parte vários com mestrado e doutorado e que não sabem ler e escrever direito. $\dot{E}$ a banalização do ensino superior... e das pósgraduações. (GFP Escola 7) 
Os participantes abordam também como dificuldade para qualificar a graduação o grande número de alunos que trabalham durante o dia para pagar seus estudos no período noturno.

Eu acho que o que dificulta é a questão de ser um curso noturno, onde o aluno tem um perfil de trabalhar o dia inteiro e vem para aula a noite. Tem alguns dias em que realmente a gente percebe que eles estão exaustos. (GFP Escola 2)

Nossa maior dificuldade é que não tinha enfermagem noturno, era só diurno, e isso era muito difícil porque a pessoa tinha que largar o emprego pra poder estudar e aí vem a questão financeira. Acho que a maior dificuldade hoje pode-se dizer que é a questão financeira, você conciliar que você tem que trabalhar pra você se manter aqui. Então isso acaba dificultando. (GFA Escola 6)

Esses dados indicam a necessidade de os cursos considerarem a preocupante base cultural e condição socioeconômica dos estudantes de enfermagem na definição dos projetos pedagógicos, no enfrentamento das debilidades. Um estudo sobre o perfil sociodemográfico de discentes dos cursos de Enfermagem reafirma esses resultados ao evidenciar que a democratização de acesso ao ensino superior propiciou uma tendência dos cursos de graduação em Enfermagem de terem estudantes que necessitam trabalhar ou receber financiamento para se sustentar durante seu processo de formação ${ }^{12}$. Em nosso estudo, a necessidade de trabalhar, segundo os participantes, determina, além do cansaço, que esses alunos apresentem restrições para vivenciar os projetos extra-curriculares e experiências em projetos de pesquisa e extensão. Assim, o trabalho é um fator que pode influenciar desfavoravelmente o rendimento acadêmico $^{16}$.

Apesar dos desafios expostos, os participantes dos grupos focais identificam também o ingresso de alunos com clareza sobre a escolha do curso superior, interessados na formação e motivados a serem bons profissionais. Esses alunos são caracterizados pela busca de oportunidades para além das oferecidas no currículo-padrão e pela participação em projetos de pesquisa e extensão.

Os alunos daqui são alunos dedicados, o vestibular seleciona muito isso. Então são alunos que desde cedo participam de projetos de pesquisa, projetos de extensão, atividades de ensino. Uma característica, por exemplo, daqui é a Semana de Enfermagem, são os alunos que organizam. Então eles têm essa visão também de organização de eventos, promover cursos. (GFP Escola 2)
Evidencia-se que a expansão dos cursos de graduação em Enfermagem, principalmente nas instituições de ensino privadas, influencia na definição de um novo perfil dos estudantes, representando desafios e possibilidades para a formação dos enfermeiros, sendo fundamental que o projeto pedagógico e a organização curricular dos cursos sejam adequados de acordo com esse novo contexto.

\section{Segundo desafio: a transformação do modelo de atenção em saúde}

Os resultados indicam que a graduação em enfermagem tem possibilitado reflexões sobre a necessidade de transformação dos modelos de atenção em saúde. Os participantes revelam o investimento das escolas em cenários diversificados de aprendizagem e a consonância da formação com as políticas inovadoras na área de saúde. Sinalizam também o movimento de articulação teoria e prática e ensino-serviço construído nos cursos.

Então, um dos diferenciais daqui, que a gente vê, é que eles buscaram inserir a gente na prática hospitalar e dos PSFs também mais cedo. A gente no terceiro período já frequentava o PSF, e não deixaram pra dar só a teoria primeiro e depois colocar a gente no campo. Eles já colocaram a gente pra trabalhar junto, teoria e prática, essa é uma das coisas que fazem diferença pra gente. (GFA Escola 1)

Então a todo momento o nosso estágio, ele é muito bom, pra gente sair preparado, baseando nas políticas de saúde, colocar o acadêmico o momento todo com a prática, então desde o primeiro período a gente vai pras ruas, a gente vai pro campo, e isso é bom, o aluno não fica na teoria, ele vê a prática (GFA Escola 4)

0 trabalho articulado entre o sistema de saúde e as instituições formadoras é imprescindível para uma proposta de ação estratégica de transformação da organização dos serviços e dos processos formativos, das práticas de saúde e das práticas pedagógicas. Nessa perspectiva, a formação para a área da saúde deveria ser evidenciada como construção da educação em serviço/ educação permanente em saúde: agregação entre desenvolvimento individual e institucional, entre serviços e gestão setorial e entre atenção à saúde e controle social' ${ }^{1}$. A articulação ensino-serviço é uma estratégia que possibilita a reflexão sobre a realidade da produção de cuidados e a necessidade de transformação do modelo assistencial vigente, abrangendo a transformação das práticas profissionais ${ }^{17}$. 
Pode-se afirmar que, no contexto da expansão dos cursos de graduação, há indicativos de que as escolas de enfermagem contribuem para a transformação dos modelos de atenção, especialmente pela incorporação da promoção da saúde como decisão política para a formação, ${ }^{18}$ reflexo de um novo entendimento sobre o sistema de saúde. Destacam-se também as iniciativas desenvolvidas nos cursos que apostam, desde os períodos iniciais, nos mecanismos de articulação ensinoserviço, na formação crítico-reflexiva:

Eu acho que enfermeiro tem aos montes, mas enfermeiro qualificado é difícil. Então eu acho que a concepção da universidade foi essa, tanto que eles tentam fazer a diferença, já inserir em prática a partir do terceiro período, a partir do primeiro agora né? Primeiro ou segundo, não sei (...) E isso é bastante interessante porque você vai sendo, vai se construindo um profissional mais crítico ... com mais tempo de prática, mais teórico. Mais preparado... Mais seguro. (GFA Escola 1)

Então o SUS nos trouxe possibilidades de ampliar essas perspectivas de trabalho em saúde e aí, consequentemente, o enfermeiro começa a ter que repensar (...) a gente realmente teve que parar, rediscutir a formação, reorientar nossa prática e reconduzir qual seria nossa sala de aula. Eu vi isso acontecendo aqui durante esses 25 anos (...) então eu diria que hoje... a gente conseguiu individualmente romper uma série de paradigmas com a nossa formação, com o nosso ponto de vista, com a nossa forma de enxergar a profissão, conseguimos romper inclusive com a vaidade, de que sou dono do saber e a minha sala de aula é soberana. Então eu vou passar aquilo que eu acredito que eu devo, a gente fez vários movimentos no sentido de romper com isso, você realmente conhece muito do seu ofício, mas esse ofício precisa ser revisto, precisa ser recondicionado e reconduzido. Vi vários pares meus aqui fazendo esse movimento, inclusive eu fui uma delas, e tive que me submeter no meio da carreira, lá para o início da década de 2000, a um estágio voluntário na Secretaria Estadual de Saúde com a querida e respeitosa XXX, que me deu a oportunidade de estar lá todas as tarde durante um ano e meio, voluntariado, para entender um pouco das políticas, da prática, $e$ poder enfrentar aquilo que eu me dizia apta a fazer (...) como eu, acho que cada um fez o seu próprio movimento e eu diria que hoje a gente vive um momento na escola de muitas mudanças... (GFP Escola 12)
A inserção dos alunos em projetos de pesquisa e de extensão desde os períodos iniciais também tem sido valorizada pelas escolas, como evidenciam os trechos a seguir:

É extensão e pesquisa, eu acho que a última grande cartada do ensino, a gente abriu os olhos e reconheceu o que é interdisciplinar, a enfermagem sai... daquela redoma de que a gente vai dar conta de tudo, e o SUS tem mostrado pra gente a importância da equipe interdisciplinar. Então aqui no XXX a gente tem tentado reunir em torno do instituto todos os cursos, fazer ações integradas, projetos de pesquisa integrados, projetos de extensão juntos... isso é valorizado no SUS, e o aluno não tinha muitas vezes essa visão. Agora, junto com as políticas públicas, eles estão entendendo que existe também a participação do outro profissional e que isso vai colaborar pra fortalecer, por exemplo, o cuidado do principio da integralidade, da equidade e de outros pilares do SUS. (GFP Escola 12)

Eu acho que o que enriquece mais ainda quando a gente tá pensando nas políticas, em termos de promoção e prevenção da saúde. Eu acho que por muito tempo a gente trabalhou com as políticas muito do ponto de vista curativo, e hoje não, o foco do projeto pedagógico, ele foca na promoção e prevenção; então, quando eu estou com os alunos lá na numa creche e aí eles se deparam com situações de violência à criança, eles já referenciam a uma outra política que não só a politica da assistência que eu disse, mas da violência, e buscam parceria com a psicologia porque a gente não dá conta de resolver isso sozinho e de fazer uma intervenção local. Então eu acho que esse foco que é a grande mudança, o que faz o diferencial hoje. (GFP Escola 12)

As instituições formadoras em enfermagem devem potencializar espaços que permitam o desenvolvimento da pesquisa, extensão e formação associados à inserção do aluno no sistema público de saúde. É preciso haver uma integração das demandas políticas e sociais aos interesses locais para o alcance de uma proposta de atenção de qualidade. Isso implica repensar diversos pontos como: 0 envolvimento dos diferentes grupos inseridos no processo educacional e de saúde; a relação da formação profissional em enfermagem e sociedade e, em especial, seu espaço e responsabilidade no contexto das políticas públicas de saúde e educação $0^{6}$.

Contudo, permanece o desafio de associar as mudanças requeridas na graduação para impactar a transformação dos 
modelos de atenção com o novo perfil de alunos que "optam" pelos Cursos de Enfermagem.

Esse desafio está, sobretudo, na necessidade de definição de estratégias para superar deficiências culturais, econômicas e sociais do "novo" aluno que ingressa nos cursos, para além dos subsídios para financiar o acesso à educação superior $^{16}$. Atividades de nivelamento, monitorias e acompanhamento psicopedagógico podem ser alternativas interessantes para qualificar a formação dos enfermeiros no contexto da expansão dos cursos de graduação.

É possível evidenciar que as escolas de enfermagem têm avançado em propostas inovadoras de articulação ensinoserviço-comunidade com inserção precoce dos estudantes em atividades de pesquisa, extensão e integração com os serviços de saúde, o que pode potencializar a orientação da formação para os problemas concretos da realidade do sistema de saúde. Contudo, há de se cuidar para que a oportunidade de vivenciar as atividades extramuros sejam equânimes nos cursos, sem excluir o grupo de alunos que, justamente, em função da necessidade de trabalhar para se manter na Universidade, deixam de experienciar as inovações com potencial para transformar o ensino.

Ainda assim, os resultados do estudo permitem indicar que o acesso ao ensino superior, no contexto da expansão das escolas de enfermagem, tem potencial para transformar 0 modelo de atenção. 0 fato de o perfil dos alunos dos cursos de enfermagem se constituir de profissionais já inseridos no mercado em saúde é um elemento que contribui com essa análise. Em especial, visualiza-se que o contexto da graduação em Enfermagem no Brasil pode possibilitar a qualificação de técnicos de enfermagem, e repercutir positivamente nos serviços de saúde.

Essa indicação deve-se à possibilidade de a graduação ampliar o referencial crítico e reflexivo dos estudantes, evidenciado no estudo na compreensão expressa por eles de uma nova perspectiva sobre o cuidado em saúde, o que pode se reverter em novas práticas, ainda que não haja ascensão de categoria profissional e ocupação de novos postos no mercado de trabalho.

Assim, apontam-se como consideraç̃̃es importantes reveladas no estudo as implicações da expansão dos cursos de enfermagem no perfil dos alunos e a possibilidade de transformar ensino e modelo de atenção.

\section{CONCLUSÃO}

Conclui-se que, no contexto da expansão do ensino superior, emergem desafios para a formação do enfermeiro relacionados à mudanças no perfil dos estudantes que ingressam nas escolas de enfermagem e consequente implicação na qualificação do cuidado e transformação dos modelos de atenção em saúde.

A mudança do perfil decorre da democratização do acesso ao ensino superior e indica a necessidade de as escolas adequarem seu projeto pedagógico e sua organização curricular de forma a compensar o déficit teórico e cultural dos novos alunos.

Há indicativos de que as escolas de enfermagem contribuem para a transformação dos modelos de atenção seja pelas inovações no processo ensino-aprendizagem com incorporação de uma nova concepção sobre o sistema de saúde, bem como pela oportunidade de desenvolver uma formação crítico-reflexiva de trabalhadores já inseridos no mercado de trabalho em saúde com reflexos na qualificação do cuidado.

0 estudo contribui com reflexões a respeito da formação do enfermeiro no Brasil e a discussão sobre a necessidade de regulação e estabelecimento de parâmetros de qualidade para que, além da ampliação quantitativa de vagas, a expansão signifique também investimentos em profissionais que intervenham propositivamente nos modelos de atenção à saúde.

\section{REFERÊNCIAS}

1.Ceccim RB, Feuerwerker LCM. 0 quadrilátero da formação para a área da saúde: ensino, gestão, atenção e controle social. PHISIS: Revista de Saúde Coletiva. 2004; 14(1):41-65.

2.Faustino RLH, Moraes MJB, Oliveira MAC, Egry EY. Caminhos da formação de enfermagem: continuidade ou ruptura? Revista Brasileira de Enfermagem. 2003; 56(4):343-347.

3.Brasil. Ministério da Educação e Cultura. Lei 9394 de 20 de dezembro de 1996. Estabelece as Diretrizes e bases da Educação Nacional. Diário Oficial da União, Brasília, 23 dez. 1996. Seção 1:27833-41.

4.Brasil. Ministério da Educação e Cultura. Conselho Nacional de Educação Brasil. Câmara de Educação Superior. Resolução CNE/CES nº 03 de 07 de novembro de 2001: Diretrizes Curriculares Nacionais do Curso de Graduação em Enfermagem. Diário Oficial da União, Brasilia, 9 nov. 2001. Seção 1:37.

5.Silva KL, Sena RR. A formação do enfermeiro: construindo a integralidade do cuidado. Revista Brasileira de Enfermagem. 2006; 59(4):488-91.

6.Kruse MHL, Meyer DE. Acerca de Diretrizes Curriculares e projetos pedagógicos: um início de reflexão. Revista Brasileira de Enfermagem. 2003; 56(4):.

7.Vieira ALS, Garcia ACP, Filho AA, Pierantoni CR, Ferraz CP, Oliveira ES, et al. Tendências do sistema educativo no Brasil: medicina, enfermagem e odontologia. In: Ministério da Saúde. Observatório de Recursos Humanos em Saúde no Brasil: estudos e análises. Brasilia, 2004.

8. Teixeira E, Vale EG, Fernandes JD, Sordi MRL. Trajetória e tendências dos cursos de enfermagem no Brasil. Rev Bras Enferm 2006, 59(4): 479-87

9.GamboaSS. A dialética na pesquisa em educação: elementos de contexto. In: Fazenda I (Org.). Metodologia da pesquisa educacional. 2. ed. São Paulo: Cortez, 1991. p.104 
10.Tanaka OY, Melo C. Avaliação de Programas de Saúde do Adolescente: um modo de fazer. São Paulo: Edusp, 2001.

11. Bardin L. Análise de Conteúdo. Lisboa. Edições 70. 1979

12.Brito AMR, Brito MJM, Silva PAB. Perfil sociodemográfico de discentes de enfermagem de instituições de ensino superior de Belo Horizonte. Escola Anna Nery Revista de Enfermagem. 2009; 13(2):328-333.

13.Varella, T. C., Matsumoto, K. 0 trabalho do enfermeiro no Brasil: analisando oferta e demanda no mercado. In: PIERANTONI, C.R.; VIANA, A.L. Educação e Saúde. São Paulo: Hucitec, 2010. Cap. 4, p. 82-97.

14.Brasil. Ministério da Saúde. Mercado de trabalho em saúde: dimensões setoriais, jurídico-institucionais e ocupacionais. Um estudo a partir da RAIS/MTE: relatório de primeiro estudo. Belo Horizonte, 2002. 791.p

15.Neves CEB, Raizer L, Fachinetto RF. Acesso, expansão e equidade na educação superior: novos desafios para a política educacional brasileira. Sociologias. 2007; 9(17):124-157.

16. CostaZS, Leite JL, Sanchez S. Estudo de alguns fatores que influenciam o rendimento do estudante de enfermagem. Revista Brasileira de Enfermagem. 1982; 35(1): 102-130.

17.Albuquerque VS et al. A Integração Ensino-serviço no Contexto dos Processos de Mudança na Formação Superior dos Profissionais da Saúde. Revista Brasileira de Educação Médica. 2008; 32 (3): 356-362.

18.Silva KL, Sena RR, Grillo MJC, Horta NC. Formação do enfermeiro: desafios para a promoção da saúde. Esc Anna Nery Ver Enferm 2010 abr-jun: 14(2): 368-376.

\section{NOTA}

${ }^{\mathrm{a}}$ Resultado de Pesquisa financiada pela Fundação de Amparo à Pesquisa do Estado de Minas Gerais (FAPEMIG) processo APQ 02100-09. 